\title{
Review Article \\ Infectious Keratitis: Secreted Bacterial Proteins That Mediate Corneal Damage
}

\author{
Mary E. Marquart and Richard J. O'Callaghan \\ Department of Microbiology, University of Mississippi Medical Center, 2500 N. State Street, Jackson, MS 39216, USA \\ Correspondence should be addressed to Richard J. O’Callaghan; rocallaghan@umc.edu
}

Received 31 May 2012; Accepted 12 December 2012

Academic Editor: Andrew G. Lee

Copyright (C) 2013 M. E. Marquart and R. J. O'Callaghan. This is an open access article distributed under the Creative Commons Attribution License, which permits unrestricted use, distribution, and reproduction in any medium, provided the original work is properly cited.

\begin{abstract}
Ocular bacterial infections are universally treated with antibiotics, which can eliminate the organism but cannot reverse the damage caused by bacterial products already present. The three very common causes of bacterial keratitis-Pseudomonas aeruginosa, Staphylococcus aureus, and Streptococcus pneumoniae-all produce proteins that directly or indirectly cause damage to the cornea that can result in reduced vision despite antibiotic treatment. Most, but not all, of these proteins are secreted toxins and enzymes that mediate host cell death, degradation of stromal collagen, cleavage of host cell surface molecules, or induction of a damaging inflammatory response. Studies of these bacterial pathogens have determined the proteins of interest that could be targets for future therapeutic options for decreasing corneal damage.
\end{abstract}

\section{Introduction}

The bacterial agents of infectious keratitis that have been studied in considerable detail are three of the most common causes of such infections, namely, Staphylococcus aureus, Streptococcus pneumoniae, and Pseudomonas aeruginosa [1]. The mechanisms underlying the tissue damage occurring during these infections have been studied in animal models. These infections are initiated by injection of bacteria into the corneal stroma, usually of New Zealand rabbits, or by the application of a topical drop of bacteria to a scarified cornea, usually of a mouse [2]. Important to this research is the relative virulence of three forms of a bacterial strain, namely, the unaltered parent strain, its mutant deficient in a single specific gene coding for a secreted protein, and that same mutant strain following insertion of a functional copy of the mutated gene, a rescued strain. If the parent and rescue strains have statistically equivalent virulence and the mutant has significantly less virulence, then the mutated gene is recognized as a key virulence factor for the cornea [3]. An additional method for establishing a specific gene as a virulence factor is to demonstrate that insertion of this specific gene into a nonpathogenic strain can significantly increase the virulence [3]. These types of genetic analysis of virulence have defined multiple virulence factors for each of the three organisms commonly causing keratitis.

The importance of secreted proteins to keratitis can be illustrated by the study of certain nonpathogenic strains of bacteria. One observation that is not generally recognized, but is very important to consider, is that bacteria can be injected into a rabbit cornea and there grow from a small inoculum to millions of bacteria without causing any harm to the eye $[4,5]$. For instance, Pseudomonas putida has been shown to grow well without mediating inflammation or corneal damage. This organism has LPS and other surface molecules, but it does not secrete proteins with corneal toxicity. This harmless infection is unlike that seen in an infection with the same $P$. putida strain after it has been modified by the insertion of a plasmid bearing a single $P$. aeruginosa gene coding for a secreted protease known to be a corneal virulence factor [4]. In fact, the secretion of any one of the three known $P$. aeruginosa proteases can result in a virulent infection [5].

The value of knowing the mechanisms of bacterial corneal virulence relates to the need to limit such mechanisms before the tissue damage deprives the eye of vision. Application 
of an antibiotic to an infected eye can eliminate the infecting bacteria, but the damaging bacterial proteins already secreted can continue to mediate harmful inflammation and act directly to damage the cornea [6]. The inclusion of a steroid during antibiotic therapy helps control the inflammatory process, but the actions of the secreted proteins are not affected by such therapy $[7,8]$. Knowledge of the key mediators of tissue damage must be known to allow subsequent development of adjunct therapies to limit the action of these bacterial proteins. The prospect of using the immune system to inhibit these secreted bacterial proteins has a merit, but the bacterial enzymes found to be active in damaging corneal tissue may be poor immunogens or the antibody produced may not be effective in impeding the enzymatic activity [9]. Thus, the mechanisms of keratitis have partially evaded the benefit of our current therapies. Also problematic is the emergence of bacteria with greater resistance to those antibiotics that were highly successful for many previous years; delays in obtaining an effective therapy provides time for the bacterial population to expand and to continue secreting the damaging proteins.

\section{Pseudomonas aeruginosa}

Pseudomonas corneal infections typically are associated with the use of contact lenses; that is, this is a man-made disease which was rarely a problem during the centuries prior to the contact lens use [10-12]. The organism, seen as a single gram-negative rod, is found in the environment, especially in moist places, so it is often available to contaminate the contact lens cases [10]. Its adherence to plastic, coupled with its resistance to disinfectants, favors its introduction into the eye. These organisms can react with a corneal defect in the epithelium and they can pass through the epithelial barrier to the corneal stroma [13]. Once these organisms reach the corneal stroma, the infections can rapidly progress toward melting of the cornea, an event attributed to the bacterial proteases, the activation of matrix metalloproteinases, and a damaging immune response that delivers among other things both reactive oxygen intermediates and host proteases [5].

$P$. aeruginosa is capable of secreting at least seven different proteases; these are elastase A (Las A), elastase B (Las B) [14], modified elastase [15], alkaline protease (AP), protease IV, pseudomonas aeruginosa small protease (PASP) [15], and the large exoprotease (Lep A) [16]. Las A, Las B, modified elastase, and AP are metalloproteinases and may be produced by only some strains [17]. These metalloproteases, especially Las B and AP, have been well studied in terms of their potential contribution to keratitis. These enzymes, especially Las $\mathrm{B}$, upon injection into the corneal stroma can mediate considerable corneal damage $[18,19]$. However, mutation of any one of these genes does not result in significantly reduced virulence of the organism [20-22]. Also, data exist showing that a strain with the potential to produce Las B fails to produce the enzyme during keratitis [23]. P. putida, when supplied with a plasmid-borne gene for Las B, secretes Las B and demonstrates significant virulence in the infected rabbit cornea [5].
Lep $\mathrm{A}$ is a large protease that has been postulated to be a serine protease $[16,24]$. The enzyme has been shown to be a virulence factor in a nonocular model of infection, but to date there are no published studies of its role in an ocular infection. An important study on Lep A showed that this enzyme can cleave a host transmembrane protein, designated the protease-activated receptor, which, when cleaved, can induce the production of cytokines [16]. This study helps explain the inflammation that results when the bacteria producing proteases interact with corneal cells. This finding may also clarify the failure of $P$. putida to cause inflammatory changes as it grows in the cornea whereas the same stain engineered to produce a $P$. aeruginosa protease causes significant inflammation.

In contrast to the findings with the metalloproteases, the serine protease PIV is produced by essentially all strains able to cause keratitis $[25,26]$. Mutation of the PIV gene has been shown to reduce the corneal virulence and the corneal virulence was restored following the insertion into the mutant strain of a plasmid coding for functional PIV [25]. When a PIV-coding plasmid was inserted into $P$. putida, the organism acquired a significant amount of corneal virulence [4]. PIV is able to cleave many proteins; in fact, few proteins with lysine escape cleavage by this protease [27, 28]. PIV will cleave poly-L-lysine to small peptides and free lysine. Cleaved by PIV are a variety of host defense proteins including immunoglobulins, complement components, antimicrobial peptides, and surfactants [27-29]. This protease contributes to virulence yet it is inefficient in cleaving collagens, the chief structural component of the corneal stroma. PIV has a molecular weight of 27,384 daltons and it can aggregate following exposure to SDS to enzymatically active masses of $>200,000$ daltons $[27,28]$. Extensive immunizations with recombinant PIV were needed to produce even a relatively small amount of antibody to recombinant PIV or native PIV [9]. The antibodies that were produced failed to inhibit the PIV catalytic activity or to provide protection from corneal damage due to the injection of active enzyme [9]. The enzyme activity is susceptible to TLCK, a serine protease inhibitor, but unfortunately TLCK is highly toxic for eyes [28]. The development of a nontoxic inhibitor could be very useful as an adjunct therapy for treating these infections.

The PASP protease has recently been analyzed relative to its role in keratitis and its properties as an enzyme [15, 30,31]. The PASP gene is found in all strains tested and western blots of culture supernatants indicate that it is commonly expressed and secreted by both clinical isolates and established lab strains [30]. A mutant lacking the PASP gene was engineered and found to have significantly less virulence than its parent or its rescued strain [31]. The reduced virulence of the PASP-deficient mutant was demonstrated in both the rabbit intrastromal injection model and the mouse scratch model of keratitis. Injection of purified PASP into the rabbit cornea results in the destruction of the epithelium and the formation of erosions that can reach into the stroma [30]. PASP, like PIV, is not neutralized by antibody to the recombinant PASP protein and the antibody does not protect the cornea from the injected enzyme or active infection [30]. 
The native PASP protein as found in culture supernatants has a molecular weight of 18,500 daltons $[15,30]$. Studies of the purified enzyme or its recombinant protein showed that, unlike PIV, PASP does not efficiently cleave many host proteins $[15,30]$. However, PASP is able to cleave collagens and this trait further distinguishes PASP from PIV. Cleavage of collagen by PASP suggests that this enzyme could be important in the destruction of the cornea [30]. PASP will cleave peptides with lysine or arginine and it can convert poly-Larginine or poly-L-lysine to small peptides and free amino acids. PASP appears to be a serine protease that is susceptible to serine protease inhibitors (e.g., TLCK) and partially inhibited, in a non-dose-dependent fashion, by high concentrations of EDTA ( $>100 \mathrm{mM})$. Enzymatic activity may require the formation of a homodimer in order to create the triad of three amino acids that form the active catalytic site [31].

The possibility exists that PIV provides the bacteria with a defense against multiple host defense molecules whereas PASP is active in cleaving the collagen-based structure of the cornea. Once a sizeable population of $P$. aeruginosa is established in a tissue site, a great deal of host response and tissue damage occurs before the infection is cleared.

\section{Streptococcus pneumoniae}

Recent attention has been given to $S$. pneumoniae (pneumococcus) as a major cause of conjunctivitis outbreaks; however, this organism is also a common cause of infectious keratitis. Some epidemiologic studies identify the pneumococcus as the top cause of bacterial keratitis [32-39]. Most other reports show this bacterium and other Streptococcus species to be the causative agents most commonly encountered after $P$. aeruginosa and/or S. aureus [40-49]. Pneumococcal keratitis is not typically contact lens associated like $P$. aeruginosa, but predisposing conditions such as ocular trauma or surgery are factors in this disease $[32,33,36,39,41,48,50-54]$.

The outer capsule of S. pneumoniae, while not protein but rather polysaccharide in composition, is likely the single most studied virulence factor of this bacterium. Pneumococcus normally resides in the human nasopharynx, and studies that date back to early bacterial virulence and transformation experiments such as those of Griffith [55] and Avery et al. [56] determined that the polysaccharide capsule (i.e., the characteristic that provides a "smooth" colony appearance) is the component necessary for S. pneumoniae to establish virulence and survive the host immune system. The central dogma of pneumococcal virulence in infections such as pneumonia, otitis media, meningitis, and septicemia is that noncapsular bacteria are avirulent. This long held rule was proven to be untrue for keratitis, as noncapsular strains were shown to cause as severe keratitis as their capsular counterparts in intrastromal infection models $[57,58]$.

Other than the capsule, the pneumococcus possesses a variety of proteins that have been characterized as virulence factors in nonocular models of disease. One such protein is pneumolysin, which is a toxin belonging to the family of bacterial cholesterol-dependent cytolysins. Pneumolysin is a $53 \mathrm{kDa}$ protein that does not possess any known secretion signal sequence. This cytolysin was long thought to be an intracellular protein released from the bacteria upon cell lysis [59-61] and more recently reported to be cell wall associated [62]. The mode of action of pneumolysin is the binding of monomers to cholesterol in host cell membranes, oligomerization at the membrane into 30-50 mers, and pore formation resulting in host cell lysis [63-65]. Lower concentrations of pneumolysin have been reported to stimulate leukocyte migration [66] and activate complement [67], thus stimulating the host inflammatory response and causing immunomediated damage to host tissues. Johnson and Allen first identified pneumolysin as responsible for ocular tissue damage during pneumococcal keratitis and characterized the biochemical features in vitro and the role in corneal virulence in vivo $[68,69]$. Pneumolysin was verified to play a major role in keratitis as evidenced by reduced corneal virulence of a pneumolysin-deficient strain of S. pneumoniae compared to its parent strain in a rabbit intrastromal infection model [70]. Mutation of the complement activation domain of pneumolysin also resulted in decreased corneal virulence, particularly inflammation [71]. Added to these findings was that induction of leukopenia in rabbits resulted in significantly decreased severity of corneal damage following challenge with purified pneumolysin, indicating that pneumolysin was at least partly responsible for triggering the inflammatory response and causing immunomediated damage [72]. Moreover, these and more recent studies have shown that pneumococcal keratitis continues to worsen in animal models when the bacteria have either reached a very low number or have been completely cleared [58, 71, 73, 74], underscoring the fact that corneal damage occurs despite eradication of the bacteria by antibiotics.

Efforts to find feasible pneumolysin inhibitors for the cornea have led to the use of soluble cholesterol as a topical therapy. Cholesterol was long known to be effective in inhibiting the hemolytic activity of pneumolysin in vitro [75], so this concept was employed in vivo. Topical cholesterol was shown to significantly reduce corneal inflammation in pneumococcal keratitis, purportedly by acting as a competitor for host cholesterol and neutralizing pneumolysin [76, 77]. Another attempt at targeting pneumolysin was the use of active and passive immunization in an animal model of keratitis $[73,78]$.

Proteins other than pneumolysin have been shown to be important for virulence in nonocular pneumococcal diseases but have not been associated with keratitis to date. Most of these proteins are located on the bacterial cell surface. A detailed review of pneumococcal virulence proteins is described elsewhere [79]. Choline-binding proteins such as pneumococcal surface proteins A and C (PspA and PspC) are anchored by their bonds to choline in the cell wall. Other proteins are those containing LPXTG motifs that are recognized by bacterial sortase enzymes and are placed on the cell surface. One pneumococcal LPXTG protein of interest is neuraminidase $\mathrm{A}(\mathrm{Nan} \mathrm{A})$, which cleaves $\mathrm{N}$-acetylneuraminic acid from host cell components and is suggested to be important for the binding of pneumococci to conjunctival epithelial cells by degrading host cell mucin [80]. A variety of surface-associated proteins that do not fall into the categories of choline-binding proteins or LPXTG proteins have also 
been identified as involved in adherence, immune evasion, immune activation, and enzymatic reactions in nonocular models. Finally, at least four zinc metalloproteinases, including an IgA protease, have been identified with conflicting reports of their cellular locations. One of these proteases, $\mathrm{ZmpC}$, has recently been shown to induce ectodomain shedding of a membrane-associated mucin from cultured conjunctival and corneal epithelial cells [81]. Much remains unknown, however, as to the factors other than pneumolysin that contribute to pneumococcal keratitis.

\section{Staphylococcus aureus}

S. aureus is the most common cause of bacterial keratitis and an important cause of other ocular infections [82-87]. This gram-positive coccus is found in human carriers who retain the organism in their anterior nares, throat, and perianal body sites [88]. Specific strains of bacteria found in the flora around the eye provide the source of organisms that infect the eye [89]. Humans are one reservoir for this organism, and multiple animals, especially pigs, have had an important role in the epidemiology of S. aureus [90]. Keratitis occurs in individuals whose eyes are compromised by any of multiple changes including ocular surgery, contact lens use, trauma, viral infection, or other illnesses [91-93]. S. aureus is well known for its ability to evolve mechanisms of antibiotic resistance, making these infections among the most difficult to treat, and antibiotic resistance has increased since 2000 [94-97]. Although the antibiotic resistance of S. aureus is well known, what is less well recognized is that the gene transfer mechanisms that created the highly resistant strains can also transfer virulence traits [98-100]. Bacteriophage provides horizontal transfer of individual genes as well as clusters of virulence traits in a genetic unit designated as a pathogenicity island [98]. Individual strains can develop a set of genes that allow their emergence as a cause of lifethreatening infections.

The mechanisms involved in the initiation of keratitis are not yet understood. S. aureus has been shown to bind to human corneal cells in culture, a reaction mediated by the fibronectin-binding protein on the bacterial surface [101]. Binding to the cornea can also be mediated by a collagenbinding adhesin on the $S$. aureus surface [102]. Despite this binding ability and the availability of organisms from the flora surrounding the eye, keratitis infrequently develops. Possibly the greatest barrier protecting the eye is the bactericidal enzyme phospholipase $A_{2}$, a component of the tear film $[103,104]$. Once inflammation occurs in the anterior portion of the eye, the amount of phospholipase $\mathrm{A}_{2}$ increases, thus enhancing protection against bacteria [104]. The topical application of $S$. aureus to a scarified rabbit cornea typically fails to cause an infection and results in the rapid loss of the bacteria [104]. An active infection of the rabbit cornea has been achieved by treating a bacterial inoculum on a contact lens with spermidine and applying spermidine to the eye both before and after applying the contaminated lens to the corneal surface [105]. Spermidine is able to bind to the bacterial surface and prevent bacterial killing by phospholipase $A_{2}$. There is, however, one unique strain of $S$. aureus that can infect the scarified cornea without any other treatments; this strain is susceptible to the bactericidal action of tears but has demonstrated an enhanced invasion of human corneal epithelial cells in vitro [unpublished finding]. These data suggest that keratitis is dependent on bacterial binding and rapid penetration of the corneal epithelium.

The events occurring once bacteria reach the corneal stroma have been studied in some detail. The virulence of a prototype S. aureus strain (8325-4) following its injection into the rabbit cornea was significantly reduced by a mutation of the gene coding for alpha-toxin, a lytic cytotoxin produced by nearly all S. aureus strains [106]. The alpha-toxin rescue strain had corneal virulence equivalent to that of the parent strain. Nanogram quantities of purified alpha-toxin were shown to cause extensive sloughing of the corneal epithelium, corneal edema, and severe iritis [107]. The importance of this toxin was found also in the infection of the mouse cornea [108, 109]. Alpha-toxin is now recognized as the critical virulence factor in S. aureus pneumonia in humans [110]. Research on the alpha-toxin's mechanism of action indicates that the toxin enters the cytoplasmic membrane and moves laterally until seven subunits unite into a circular arrangement forming a pore in the cytoplasmic membrane [111]. The individual toxin molecules are thought to interact with caveolin-1 in the membrane to form a pore [111-113]. Inhibitors of the alphatoxin-mediated lysis of erythrocytes have been developed by inserting lipid molecules into a cyclodextrin ring $[114,115]$. One such inhibitor containing cholesterol has been shown to reduce the virulence of infections of the rabbit cornea [114]. As was described above, the cyclodextrin-based inhibitor active against alpha-toxin is also active against pneumolysin [76].

Alpha-toxin is not the only virulence factor contributing to the tissue damage during S. aureus keratitis; important also is gamma-toxin, a two-component toxin produced by nearly all S. aureus strains $[116,117]$. Deletion of the gamma-toxin genes from a prototype strain, strain Newman, resulted in a significant loss in corneal virulence and restoration of these genes enhanced the virulence back to that produced by the parent strain [118]. A mutation in gamma-toxin or inhibition of this toxin has also been shown to reduce the virulence of endophthalmitis caused by S. aureus $[119,120]$. Gammatoxin is composed of an F component and an S component that are each nontoxic when tested alone [121, 122]. The $S$ component is thought to bind to the target cell and only then will the $\mathrm{F}$ component bind [122]. The combination of $\mathrm{F}$ and $\mathrm{S}$ can move laterally in the cell membrane and multiple F-S pairs can combine into a ring that penetrates the membrane causing cell lysis [122-124]. A cyclodextrin-based inhibitor for the gamma-toxin has very recently been identified as an inhibitor of the gamma-toxin-mediated lysis of erythrocytes, but it has not been tested yet in infected corneas [120].

Gamma-toxin is only one of several two-component toxins produced by $S$. aureus and each has its own $\mathrm{F}$ and $S$ components [122]. Gamma-toxin is composed of two proteins, either $\mathrm{HlgA}$ and $\mathrm{HlgB}$ or $\mathrm{HlgC}$ and $\mathrm{HlgB}$; likewise the Panton-Valentine leucocidin (PVL), a well-recognized toxin, is composed of its two proteins, LukF-PV and LukS-PV [122]. Lesser known proteins involved in toxic activity 
include three S-type proteins LukM, LukS-R, and Luk E and two F-type proteins LukF-R and Luk D [122-124]. There is about $60-70 \%$ sequence homology among the various $\mathrm{F}$ components and a fairly similar degree of homology among the multiple S components [122]. The two-component toxin systems of $S$. aureus are complicated by the fact that the $\mathrm{F}$ component of one toxin can bind to the $\mathrm{S}$ component of another toxin [122]. Therefore, multiple unique toxins can be formed by one component from each of two different toxins (e.g., the $\mathrm{F}$ of one toxin with the $\mathrm{S}$ of another toxin). Each combination of an $\mathrm{F}$ and an $\mathrm{S}$ component can have its own specific toxicity [122]. How these toxins relate to corneal damage is yet to be resolved, but because these toxins are homologous with gamma-toxin, it is likely that at least one such toxin has corneal toxicity.

Another molecule with proven ability to serve as a corneal virulence factor is the setnm-1 gene [125]. This gene is a part of a cluster of genes for super-antigen-like proteins involved in virulence for infections in nonocular sites [126]. These genes are found in a pathogenicity island on the chromosome of many $S$. aureus isolates and they are thought to have been derived from a phage genome [126]. The genes in this island, other than setnm-1, are known to inhibit host immune mediators such as complement or IgA. Only setnm1 has been shown to mediate corneal damage; that is, a mutant deficient in this gene has significantly reduced corneal virulence as compared to its parent and rescued strains [125]. It is not yet clear how setnm-1 functions as a virulence factor, but one possibility is that it has protease activity [127]. Injection of the protein produced by the setnm-1 gene can cause extensive corneal damage, an event not expected for a super-antigen-like protein.

\section{Conclusions}

The fundamental treatment of bacterial keratitis is based on the action of bactericidal antibiotic therapy to eliminate the bacteria that secrete the toxic proteins. A key issue in treatment is that the cornea has rapidly replicating bacteria prior to the onset of severe symptoms, and later, when symptoms are present, bacteria with a much reduced rate of bacterial replication predominate. Key drugs, such as fluoroquinolones, are far more effective on replicating than nonreplicating bacteria, so the treatment of the cornea needs to be prompt, aggressive, and prolonged. Global regulation of gene expression in bacteria limits the production of important toxins and enzymes until the bacteria are no longer rapidly replicating [128]. Once replication slows or stops, the toxins are secreted; thus, nonreplicating bacteria are hard to kill and they are efficient toxin producers. The points to be stressed are that prompt bactericidal therapy is a must and that the toxins once produced cannot now be eliminated without a loss of healthy tissue.

\section{References}

[1] P. Asbell and S. Stenson, "Ulcerative keratitis. Survey of 30 years' laboratory experience," Archives of Ophthalmology, vol. 100, no. 1, pp. 77-80, 1982.
[2] D. O. Girgis, G. D. Sloop, J. M. Reed, and R. J. O'Callaghan, "A new topical model of Staphylococcus corneal infection in the mouse," Investigative Ophthalmology and Visual Science, vol. 44, no. 4, pp. 1591-1597, 2003.

[3] A. A. Salyers and D. D. Whitt, Bacterial Pathogenesis, a Molecular Approach, ASM Press, Washington, DC, USA, 2nd edition, 2002.

[4] M. Traidej, A. R. Caballero, M. E. Marquart, B. A. Thibodeaux, and R. J. O'Callaghan, "Molecular analysis of Pseudomonas aeruginosa protease IV expressed in Pseudomonas putida," Investigative Ophthalmology and Visual Science, vol. 44, no. 1, pp. 190-196, 2003.

[5] B. A. Thibodeaux, A. R. Caballero, M. E. Marquart, J. Tommassen, and R. J. O'Callaghan, "Corneal virulence of Pseudomonas aeruginosa elastase B and alkaline protease produced by Pseudomonas putida," Current Eye Research, vol. 32, no. 4, pp. 373-386, 2007.

[6] R. J. O'Callaghan, "Role of exoproteins in bacterial keratitis: the Fourth Annual Thygeson Lecture, presented at the Ocular Microbiology and Immunology Group Meeting, November 7, 1998," Cornea, vol. 18, no. 5, pp. 532-537, 1999.

[7] J. A. Hobden, J. M. Hill, L. S. Engel, and R. J. O'Callaghan, "Age and therapeutic outcome of experimental Pseudomonas aeruginosa keratitis treated with ciprofloxacin, prednisolone, and flurbiprofen," Antimicrobial Agents and Chemotherapy, vol. 37, no. 9, pp. 1856-1859, 1993.

[8] J. A. Hobden, L. S. Engel, J. M. Hill, M. C. Callegan, and R. J. O'Callaghan, "Prednisolone acetate or prednisolone phosphate concurrently administered with ciprofloxacin for the therapy of experimental Pseudomonas aeruginosa keratitis," Current Eye Research, vol. 12, no. 5, pp. 469-473, 1993.

[9] B. A. Thibodeaux, A. R. Caballero, J. J. Dajcs, M. E. Marquart, L. S. Engel, and R. J. O'Callaghan, "Pseudomonas aeruginosa protease IV: a corneal virulence factor of low immunogenicity," Ocular Immunology and Inflammation, vol. 13, no. 2-3, pp. 169-182, 2005.

[10] Y. Ogushi, H. Eguchi, T. Kuwahara, N. Hayabuchi, and M. Kawabata, "Molecular genetic investigations of contaminated contact lens storage cases as reservoirs of Pseudomonas aeruginosa keratitis," Japanese Journal of Ophthalmology, vol. 54, no. 6, pp. 550-554, 2010.

[11] E. C. Poggio, R. J. Glynn, O. D. Schein et al., "The incidence of ulcerative keratitis among users of daily-wear and extendedwear soft contact lenses," New England Journal of Medicine, vol. 321, no. 12, pp. 779-783, 1989.

[12] O. D. Schein and E. C. Poggio, "Ulcerative keratitis in contact lens wearers. Incidence and risk factors," Cornea, vol. 9, supplement 1, pp. S55-S58, 1990.

[13] J. C. Ramirez, S. M. Fleiszig, A. B. Sullivan, C. Tam, R. Borazani, and D. J. Evans, "Traversal of multilayered corneal epithelia by cytotoxic Pseudomonas aeruginosa requires the phospholipase domain of exoU," Investigative Ophthalmology and Visual Science, vol. 53, no. 1, pp. 448-453, 2012.

[14] S. S. Twining, S. E. Kirschner, L. A. Mahnke, and D. W. Frank, "Effect of Pseudomonas aeruginosa elastase, alkaline protease, and exotoxin A on corneal proteinases and proteins," Investigative Ophthalmology and Visual Science, vol. 34, no. 9, pp. 2699-2712, 1993.

[15] M. E. Marquart, A. R. Caballero, M. Chomnawang, B. A. Thibodeaux, S. S. Twining, and R. J. O'Callaghan, "Identification of a novel secreted protease from Pseudomonas aeruginosa 
that causes corneal erosions," Investigative Ophthalmology and Visual Science, vol. 46, no. 10, pp. 3761-3768, 2005.

[16] Y. Kida, Y. Higashimoto, H. Inoue, T. Shimizu, and K. Kuwano, "A novel secreted protease from Pseudomonas aeruginosa activates NF- $\kappa$ B through protease-activated receptors," Cellular Microbiology, vol. 10, no. 7, pp. 1491-1504, 2008.

[17] T. I. Nicas and B. H. Iglewski, "Production of elastase and other exoproducts by environmental isolates of Pseudomonas aeruginosa," Journal of Clinical Microbiology, vol. 23, no. 5, pp. 967-969, 1986.

[18] K. Matsumoto, N. B. K. Shams, L. A. Hanninen, and K. R. Kenyon, "Cleavage and activation of corneal matrix metalloproteases by Pseudomonas aeruginosa proteases," Investigative Ophthalmology and Visual Science, vol. 34, no. 6, pp. 1945-1953, 1993.

[19] E. Kessler, H. E. Kennah, and S. I. Brown, "Pseudomonas protease. Purification, partial characterization, and its effect on collagen, proteoglycan, and rabbit corneas," Investigative Ophthalmology and Visual Science, vol. 16, no. 6, pp. 488-497, 1977.

[20] C. D. White, L. G. Alionte, B. M. Cannon, A. R. Caballero, R. J. O'Callaghan, and J. A. Hobden, "Corneal virulence of LasA protease-deficient Pseudomonas aeruginosa PAO1," Cornea, vol. 20, no. 6, pp. 643-646, 2001.

[21] C. M. Pillar, L. D. Hazlett, and J. A. Hobden, "Alkaline proteasedeficient mutants of Pseudomonas aeruginosa are virulent in the eye," Current Eye Research, vol. 21, no. 3, pp. 730-739, 2000.

[22] J. A. Hobden, "Pseudomonas aeruginosa proteases and corneal virulence," DNA and Cell Biology, vol. 21, no. 5-6, pp. 391-396, 2002.

[23] K. A. Kernacki, J. A. Hobden, L. D. Hazlett, R. Fridman, and R. S. Berk, "In vivo bacterial protease production during Pseudomonas aeruginosa corneal infection," Investigative Ophthalmology and Visual Science, vol. 36, no. 7, pp. 1371-1378, 1995.

[24] Y. Kida, T. Shimizu, and K. Kuwano, "Cooperation between LepA and $\mathrm{PlcH}$ contributes to the in vivo virulence and growth of Pseudomonas aeruginosa in mice," Infection and Immunity, vol. 79, no. 1, pp. 211-219, 2011.

[25] A. Caballero, B. Thibodeaux, M. Marquart, M. Traidej, and R. J. O'Callaghan, "Pseudomonas keratitis: protease IV gene conservation, distribution, and production relative to virulence and other pseudomonas proteases," Investigative Ophthalmology and Visual Science, vol. 45, no. 2, pp. 522-530, 2004.

[26] T. Conibear, M. Wilcox, J. R. Flanagan, and H. Zhu, "Characterization of protease IV expression in Pseudomonas aeruginosa clinical isolates," Journal of Medical Microbiology, vol. 61, part 2, pp. 180-190, 2012.

[27] L. S. Engel, J. M. Hill, A. R. Caballero, L. C. Green, and R. J. O'Callaghan, "Protease IV, a unique extracellular protease and virulence factor from Pseudomonas aeruginosa," Journal of Biological Chemistry, vol. 273, no. 27, pp. 16792-16797, 1998.

[28] A. R. Caballero, J. M. Moreau, L. S. Engel, M. E. Marquart, J. M. Hill, and R. J. O'Callaghan, "Pseudomonas aeruginosa protease IV enzyme assays and comparison to other Pseudomonas proteases," Analytical Biochemistry, vol. 290, no. 2, pp. 330-337, 2001.

[29] J. L. Malloy, R. A. W. Veldhuizen, B. A. Thibodeaux, R. J. O'Callaghan, and J. R. Wright, "Pseudomonas aeruginosa protease IV degrades surfactant proteins and inhibits surfactant host defense and biophysical functions," American Journal of
Physiology/Lung Cell Molecular Physiology, vol. 288, no. 2, pp. L409-L418, 2005.

[30] A. Tang, M. E. Marquart, J. D. Fratkin et al., "Properties of PASP: a pseudomonas protease capable of mediating corneal erosions," Investigative Ophthalmology and Visual Science, vol. 50, no. 8, pp. 3794-3801, 2009.

[31] R. J. O'Callaghan, A. Tang, M. E. Marquart, and A. R. Caballero, "Pseudomonas aeruginosa Small Protease (PASP), a keratitis virulence factor," Investigative Ophthalmology and Visual Science, vol. 53, 2012, E-abstract 6128.

[32] A. G. Al Otaibi, K. Allam, A. J. Damri, A. A. Shamri, H. Kalantan, and A. Mousa, "Childhood microbial keratitis," Oman Journal of Ophthalmology, vol. 5, no. 1, pp. 28-31, 2012.

[33] G. Bashir, A. Shah, M. A. Thokar, S. Rashid, and S. Shakeel, "Bacterial and fungal profile of corneal ulcers-a prospective study," Indian Journal of Pathology and Microbiology, vol. 48, no. 2, pp. 273-277, 2005.

[34] M. J. Bharathi, R. Ramakrishnan, S. Vasu, R. Meenakshi, and R. Palaniappan, "Aetiological diagnosis of microbial keratitis in South India-a study of 1618 cases," Indian Journal of Medical Microbiology, vol. 20, no. 1, pp. 19-24, 2002.

[35] M. J. Bharathi, R. Ramakrishnan, S. Vasu, R. Meenakshi, C. Shivkumar, and R. Palaniappan, "Epidemiology of bacterial keratitis in a referral centre in south India," Indian Journal of Medical Microbiology, vol. 21, no. 4, pp. 239-245, 2003.

[36] M. J. Bharathi, R. Ramakrishnan, R. Meenakshi, S. Padmavathy, C. Shivakumar, and M. Srinivasan, "Microbial keratitis in South India: influence of risk factors, climate, and geographical variation," Ophthalmic Epidemiology, vol. 14, no. 2, pp. 61-69, 2007.

[37] M. R. Feilmeier, K. R. Sivaraman, M. Oliva, G. C. Tabin, and R. Gurung, "Etiologic diagnosis of corneal ulceration at a Tertiary Eye Center in Kathmandu, Nepal," Cornea, vol. 29, no. 12, pp. 1380-1385, 2010.

[38] R. L. Furlanetto, E. G. V. Andreo, I. G. A. Finotti, E. S. Arcieri, M. A. Ferreira, and F. J. Rocha, "Epidemiology and etiologic diagnosis of infectious keratitis in Uberlandia, Brazil," European Journal of Ophthalmology, vol. 20, no. 3, pp. 498-503, 2010.

[39] R. Katiyar, S. Deorukhkar, and S. Saini, "Epidemiological features and laboratory results of bacterial and fungal keratitis: a five-year study at a rural tertiary-care hospital in western Maharashtra, India," Singapore Medical Journal, vol. 53, no. 4, pp. 264-267, 2012.

[40] M. J. Bharathi, R. Ramakrishnan, C. Shivakumar, R. Meenakshi, and D. Lionalraj, "Etiology and antibacterial susceptibility pattern of community-acquired bacterial ocular infections in a tertiary eye care hospital in south India," Indian Journal of Ophthalmology, vol. 58, no. 6, pp. 497-507, 2010.

[41] S. Boonpasart, N. Kasetsuwan, V. Puangsricharern, L. Pariyakanok, and T. Jittpoonkusol, "Infectious keratitis at King Chulalongkorn Memorial Hospital: a-12-year retrospective study of 391 cases," Journal of the Medical Association of Thailand, vol. 85, supplement 1, pp. S217-S230, 2002.

[42] P. Lalitha, M. Srinivasan, P. Manikandan et al., "Relationship of in vitro susceptibility to moxifloxacin and in vivo clinical outcome in bacterial keratitis," Clinical Infectious Diseases, vol. 54, no. 10, pp. 1381-1387, 2012.

[43] T. J. Norina, S. Raihan, S. Bakiah, M. Ezanee, A. T. LizaSharmini, and W. H. Wan Hazzabah, "Microbial keratitis: aetiological diagnosis and clinical features in patients admitted to Hospital Universiti Sains Malaysia," Singapore Medical Journal, vol. 49, no. 1, pp. 67-71, 2008. 
[44] S. Ramesh, R. Ramakrishnan, M. J. Bharathi, M. Amuthan, and S. Viswanathan, "Prevalence of bacterial pathogens causing ocular infections in South India," Indian Journal of Pathology and Microbiology, vol. 53, no. 2, pp. 281-286, 2010.

[45] F. Schaefer, O. Bruttin, L. Zografos, and Y. Guex-Crosier, "Bacterial keratitis: a prospective clinical and microbiological study," British Journal of Ophthalmology, vol. 85, no. 7, pp. 842-847, 2001.

[46] Z. Shalchi, A. Gurbaxani, M. Baker, and J. Nash, "Antibiotic resistance in microbial keratitis: ten-year experience of corneal scrapes in the United Kingdom," Ophthalmology, vol. 118, no. 11, pp. 2161-2165, 2011.

[47] G. Varaprasathan, K. Miller, T. Lietman et al., "Trends in the etiology of infectious corneal ulcers at the F. I. Proctor Foundation," Cornea, vol. 23, no. 4, pp. 360-364, 2004.

[48] M. D. Wagoner, S. A. Al-Swailem, J. E. Sutphin, and M. B. Zimmerman, "Bacterial keratitis after penetrating keratoplasty. Incidence, microbiological profile, graft survival, and visual outcome," Ophthalmology, vol. 114, no. 6, pp. 1073-1079, 2007.

[49] S. Yilmaz, I. Ozturk, and A. Maden, "Microbial keratitis in West Anatolia, Turkey: a retrospective review," International Ophthalmology, vol. 27, no. 4, pp. 261-268, 2007.

[50] C. B. Cosar, E. J. Cohen, C. J. Rapuano, and P. R. Laibson, "Clear corneal wound infection after phacoemulsification," Archives of Ophthalmology, vol. 119, no. 12, pp. 1755-1759, 2001.

[51] T. Lifshitz, J. Levy, F. Raiskup, I. Klemperer, and J. Frucht-Pery, "Two cases of pneumococcal keratitis following myopic LASIK," Journal of Refractive Surgery, vol. 21, no. 5, pp. 498-501, 2005.

[52] M. E. Mulet, J. J. Pérez-Santonja, C. Ferrer, and J. L. Alió, "Microbial keratitis after intrastromal corneal ring segment implantation," Journal of Refractive Surgery, vol. 26, no. 5, pp. 364-369, 2010.

[53] M. Nubile, P. Carpineto, M. Lanzini, M. Ciancaglini, E. Zuppardi, and L. Mastropasqua, "Multilayer amniotic membrane transplantation for bacterial keratitis with corneal perforation after hyperopic photorefractive keratectomy. Case report and literature review," Journal of Cataract and Refractive Surgery, vol. 33, no. 9, pp. 1636-1640, 2007.

[54] U. Rehany, G. Balut, E. Lefler, and S. Rumelt, "The prevalence and risk factors for donor corneal button contamination and its association with ocular infection after transplantation," Cornea, vol. 23, no. 7, pp. 649-654, 2004.

[55] F. Griffith, “The significance of pneumococcal types," Journal of Hygiene, vol. 27, no. 2, pp. 113-159, 1928.

[56] O. T. Avery, C. M. MacLeod, and M. McCarty, "Studies on the chemical nature of the substance inducing transformation of pneumococcal types: induction of transformation by a desoxyribonucleic acid fraction isolated from pneumococcus type III," Journal of Experimental Medicine, vol. 79, no. 1, pp. 137-158, 1944.

[57] E. W. Norcross, N. A. Tullos, S. D. Taylor, M. E. Sanders, and M. E. Marquart, "Assessment of Streptococcus pneumoniae capsule in conjunctivitis and keratitis in vivo neuraminidase activity increases in nonencapsulated pneumococci following conjunctival infection," Current Eye Research, vol. 35, no. 9, pp. 787-798, 2010.

[58] J. M. Reed, R. J. O'Callaghan, D. O. Girgis, C. C. McCormick, A. R. Caballero, and M. E. Marquart, "Ocular virulence of capsuledeficient Streptococcus pneumoniae in a rabbit keratitis model," Investigative Ophthalmology and Visual Science, vol. 46, no. 2, pp. 604-608, 2005.
[59] M. K. Johnson, "Cellular location of pneumolysin," FEMS Microbiology Letters, vol. 2, no. 5, pp. 243-245, 1977.

[60] K. Kanclerski and R. Möllby, "Production and purification of Streptococcus pneumoniae hemolysin (pneumolysin)," Journal of Clinical Microbiology, vol. 25, no. 2, pp. 222-225, 1987.

[61] C. Steinfort, R. Wilson, T. Mitchell et al., "Effect of Streptococcus pneumoniae on human respiratory epithelium in vitro," Infection and Immunity, vol. 57, no. 7, pp. 2006-2013, 1989.

[62] K. E. Price and A. Camilli, "Pneumolysin localizes to the cell wall of Streptococcus pneumoniae," Journal of Bacteriology, vol. 191, no. 7, pp. 2163-2168, 2009.

[63] P. J. Morgan, S. C. Hyman, O. Byron, P. W. Andrew, T. J. Mitchell, and A. J. Rowe, "Modeling the bacterial protein toxin, pneumolysin, in its monomeric and oligomeric form," Journal of Biological Chemistry, vol. 269, no. 41, pp. 25315-25320, 1994.

[64] P. J. Morgan, S. C. Hyman, A. J. Rowe, T. J. Mitchell, P. W. Andrew, and H. R. Saibil, "Subunit organisation and symmetry of pore-forming, oligomeric pneumolysin," FEBS Letters, vol. 371, no. 1, pp. 77-80, 1995.

[65] S. J. Tilley, E. V. Orlova, R. J. C. Gilbert, P. W. Andrew, and H. R. Saibil, "Structural basis of pore formation by the bacterial toxin pneumolysin," Cell, vol. 121, no. 2, pp. 247-256, 2005.

[66] M. K. Johnson, D. Boese-Marrazzo, and W. A. Pierce Jr., "Effects of pneumolysin on human polymorphonuclear leukocytes and platelets," Infection and Immunity, vol. 34, no. 1, pp. 171-176, 1981.

[67] J. C. Paton, B. Rowan Kelly, and A. Ferrante, "Activation of human complement by the pneumococcal toxin pneumolysin," Infection and Immunity, vol. 43, no. 3, pp. 1085-1087, 1984.

[68] M. K. Johnson and J. H. Allen, "Ocular toxin of the pneumococcus," American Journal of Ophthalmology, vol. 72, no. 1, pp. 175-180, 1971.

[69] M. K. Johnson and J. H. Allen, "The role of cytolysin in pneumococcal ocular infection," American Journal of Ophthalmology, vol. 80, no. 3, part 2, pp. 518-521, 1975.

[70] M. K. Johnson, J. A. Hobden, M. Hagenah, R. J. O’Callaghan, J. M. Hill, and S. Chen, "The role of pneumolysin in ocular infections with Streptococcus pneumoniae," Current Eye Research, vol. 9, no. 11, pp. 1107-1114, 1990.

[71] M. K. Johnson, M. C. Callegan, L. S. Engel et al., "Growth and virulence of a complement-activation-negative mutant of Streptococcus pneumoniae in the rabbit cornea," Current Eye Research, vol. 14, no. 4, pp. 281-284, 1995.

[72] J. C. Harrison, Z. A. Karcioglu, and M. K. Johnson, "Response of leukopenic rabbits to pneumococcal toxin," Current Eye Research, vol. 2, no. 10, pp. 705-710, 1982-1983.

[73] S. N. Green, M. Sanders, Q. C. Moore III et al., "Protection from Streptococcus pneumoniae keratitis by passive immunization with pneumolysin antiserum," Investigative Ophthalmology and Visual Science, vol. 49, no. 1, pp. 290-294, 2008.

[74] Q. C. Moore III, C. C. McCormick, E. W. Norcross et al., "Development of a Streptococcus pneumoniae keratitis model in mice," Ophthalmic Research, vol. 42, no. 3, pp. 141-146, 2009.

[75] M. K. Johnson, C. Geoffroy, and J. E. Alouf, "Binding of cholesterol by sulfhydryl-activated cytolysins," Infection and Immunity, vol. 27, no. 1, pp. 97-101, 1980.

[76] M. E. Marquart, K. S. Monds, C. C. McCormick et al., "Cholesterol as treatment for pneumococcal keratitis: cholesterolspecific inhibition of pneumolysin in the cornea," Investigative Ophthalmology and Visual Science, vol. 48, no. 6, pp. 2661-2666, 2007. 
[77] M. E. Sanders, N. A. Tullos, S. D. Taylor et al., "Moxifloxacin and cholesterol combined treatment of pneumococcal keratitis," Current Eye Research, vol. 35, no. 12, pp. 1142-1147, 2010.

[78] E. W. Norcross, M. E. Sanders, Q. C. Moore III et al., "Active immunization with pneumolysin versus 23 -valent polysaccharide vaccine for Streptococcus pneumoniae keratitis," Investigative Ophthalmology and Visual Science, vol. 52, no. 12, pp. 9232-9243, 2011.

[79] A. M. Mitchell and T. J. Mitchell, "Streptococcus pneumoniae: virulence factors and variation," Clinical Microbiology and Infection, vol. 16, no. 5, pp. 411-418, 2010.

[80] Y. M. Williamson, R. Gowrisankar, D. L. Longo et al., "Adherence of nontypeable Streptococcus pneumoniae to human conjunctival epithelial cells," Microbial Pathogenesis, vol. 44, no. 3, pp. 175-185, 2008.

[81] B. Govindarajan, B. B. Menon, S. Spurr-Michaud et al., "A metalloproteinase secreted by Streptococcus pneumoniae removes membrane mucin MUC16 from the epithelial glycocalyx barrier," PLoS One, vol. 7, no. 3, article e32418, 2012.

[82] T. J. Liesegang, "Bacterial keratitis," in The Cornea, H. E. Kaufman, B. A. Baron, and M. A. McDonald, Eds., ButterworthHeineman, Boston, Mass, USA, 1998.

[83] V. W. Wong, T. Y. Lai, S. C. Chi, and D. S. Lam, "Pediatric ocular surface infections: a 5-year review of demographics, clinical features, risk factors, microbiological results, and treatment," Cornea, vol. 30, no. 9, pp. 995-1002, 2011.

[84] B. H. Jeng, D. C. Gritz, A. B. Kumar et al., "Epidemiology of ulcerative keratitis in Northern California," Archives of Ophthalmology, vol. 128, no. 8, pp. 1022-1028, 2010.

[85] N. Kerr and G. A. Stern, "Bacterial keratitis associated with vernal keratoconjunctivitis," Cornea, vol. 11, no. 4, pp. 355-359, 1992.

[86] M. L. Palmer and R. A. Hyndiuk, "Contact lens-related infectious keratitis," International Ophthalmology Clinics, vol. 33, no. 1, pp. 23-49, 1993.

[87] J. W. Sowka, A. S. Gurwood, and A. G. Kabat, Handbook of Ocular Disease Management Web Site: Bacterial Keratitis, Jobson Publishing, 2001.

[88] E. Tacconelli and A. P. Johnson, "National guidelines for decolonization of methicillin-resistant Staphylococcus aureus carriers: the implications of recent experience in the Netherlands," The Journal of Antimicrobial Chemotherapy, vol. 66, no. 10, pp. 2195-2198, 2011.

[89] M. G. Speaker, F. A. Milch, M. K. Shah, W. Eisner, and B. N. Kreiswirth, "Role of external bacterial flora in the pathogenesis of acute postoperative endophthalmitis," Ophthalmology, vol. 98 , no. 5, pp. 639-649, 1991.

[90] R. Köck, J. Harlizius, N. Bressan et al., "Prevalence and molecular characteristics of methicillin-resistant Staphylococcus aureus (MRSA) among pigs on German farms and import of livestock-related MRSA into hospitals," European Journal of Clinical Microbiology and Infectious Diseases, vol. 28, no. 11, pp. 1375-1382, 2009.

[91] J. Cheung and A. R. Slomovic, "Microbial etiology and predisposing factors among patients hospitalized for corneal ulceration," Canadian Journal of Ophthalmology, vol. 30, no. 5, pp. 251-255, 1995.

[92] L. D. Ormerod, E. Hertzmark, D. S. Gomez, R. G. Stabiner, D. J. Schanzlin, and R. E. Smith, "Epidemiology of microbial keratitis in Southern California. A multivariate analysis," Ophthalmology, vol. 94, no. 10, pp. 1322-1333, 1987.
[93] D. J. Coster and P. R. Badenoch, "Host, microbial, and pharmacological factors affecting the outcome of suppurative keratitis," British Journal of Ophthalmology, vol. 71, no. 2, pp. 96-101, 1987.

[94] P. A. Asbell, D. F. Sahm, M. Shaw, D. C. Draghi, and N. P. Brown, "Increasing prevalence of methicillin resistance in serious ocular infections caused by Staphylococcus aureus in the United States: 2000 to 2005," Journal of Cataract and Refractive Surgery, vol. 34, no. 5, pp. 814-818, 2008.

[95] S. B. Dave, H. S. Toma, and S. J. Kim, "Ophthalmic antibiotic use and multidrug-resistant Staphylococcus epidermidis: a controlled, longitudinal study," Ophthalmology, vol. 118, no. 10, pp. 2035-2040, 2011.

[96] I. Morrissey, R. Burnett, L. Viljoen, and M. Robbins, "Surveillance of the susceptibility of ocular bacterial pathogens to the fluoroquinolone gatifloxacin and other antimicrobials in Europe during 2001/2002," The Journal of Infection, vol. 49, no. 2, pp. 109-114, 2004.

[97] M. McDonald and J. M. Blondeau, "Emerging antibiotic resistance in ocular infections and the role of fluoroquinolones," Journal of Cataract and Refractive Surgery, vol. 36, no. 9, pp. 1588-1598, 2010.

[98] H. Schmidt and M. Hensel, "Pathogenicity islands in bacterial pathogenesis," Clinical Microbiology Reviews, vol. 17, no. 1, pp. 14-56, 2004.

[99] M. C. Enright, "The population structure of Staphylococcus aureus," in Staphylococcus Molecular Genetics, J. A. Lindsay, Ed., pp. 29-43, Caister Academic Press, Norfolk, UK, 2008.

[100] P. R. McAdam, K. E. Templeton, G. F. Edwards et al., "Molecular tracing of the emergence, adaptation, and transmission of hospital-associated methicillin-resistant Staphylococcus aureus," Proceedings of the National Academy of Sciences of the United States of America, vol. 109, no. 23, pp. 9107-9112, 2012.

[101] B. D. Jett and M. S. Gilmore, "Internalization of Staphylococcus aureus by human corneal epithelial cells: role of bacterial fibronectin-binding protein and host cell factors," Infection and Immunity, vol. 70, no. 8, pp. 4697-4700, 2002.

[102] M. N. Rhem, E. M. Lech, J. M. Patti et al., “The collagen-binding adhesin is a virulence factor in Staphylococcus aureus keratitis," Infection and Immunity, vol. 68, no. 6, pp. 3776-3779, 2000.

[103] D. O. Girgis, J. J. Dajcs, and R. J. O’Callaghan, “Phospholipase A2 activity in normal and Staphylococcus aureus-infected rabbit eyes," Investigative Ophthalmology and Visual Science, vol. 44, no. 1, pp. 197-202, 2003.

[104] J. M. Moreau, D. O. Girgis, E. B. H. Hume, J. J. Dajcs, M. S. Austin, and R. J. O'Callaghan, "Phospholipase A2 in rabbit tears: a host defense against Staphylococcus aureus," Investigative Ophthalmology and Visual Science, vol. 42, no. 10, pp. 2347-2354, 2001.

[105] E. B. H. Hume, J. J. Dajcs, J. M. Moreau, G. D. Sloop, M. D. P. Willcox, and R. J. O'Callaghan, "Staphylococcus corneal virulence in a new topical model of infection," Investigative Ophthalmology and Visual Science, vol. 42, no. 12, pp. 2904-2908, 2001.

[106] R. J. O’Callaghan, M. C. Callegan, J. M. Moreau et al., "Specific roles of alpha-toxin and beta-toxin during Staphylococcus aureus corneal infection," Infection and Immunity, vol. 65, no. 5, pp. 1571-1578, 1997.

[107] J. M. Moreau, G. D. Sloop, L. S. Engel, J. M. Hill, and R. J. O'Callaghan, "Histopathological studies of staphylococcal alpha-toxin: effects on rabbit corneas," Current Eye Research, vol. 16, no. 12, pp. 1221-1228, 1997. 
[108] D. O. Girgis, G. D. Sloop, J. M. Reed, and R. J. O'Callaghan, “A new topical model of Staphylococcus corneal infection in the mouse," Investigative Ophthalmology and Visual Science, vol. 44, no. 4, pp. 1591-1597, 2003.

[109] D. O. Girgis, G. D. Sloop, J. M. Reed, and R. J. O'Callaghan, "Effects of toxin production in a murine model of Staphylococcus aureus keratitis," Investigative Ophthalmology and Visual Science, vol. 46, no. 6, pp. 2064-2070, 2005.

[110] C. Kebaier, R. C. Chamberland, I. C. Allen et al., "Staphylococcus aureus $\alpha$-hemolysin mediates virulence in a murine model of severe pneumonia through activation of the NLRP3 inflammasome," Journal of Infectious Diseases, vol. 205, no. 5, pp. 807-817, 2012.

[111] G. Menestrina, M. D. Serra, and G. Prévost, "Mode of action of $\beta$-barrel pore-forming toxins of the staphylococcal $\alpha$ hemolysin family," Toxicon, vol. 39, no. 11, pp. 1661-1672, 2001.

[112] S. Pany, R. Vijayvargia, and M. V. Krishnasastry, "Caveolin1 binding motif of $\alpha$-hemolysin: its role in stability and pore formation," Biochemical and Biophysical Research Communications, vol. 322, no. 1, pp. 29-36, 2004.

[113] R. Vijayvargia, C. G. Suresh, and M. V. Krishnasastry, "Functional form of caveolin-1 is necessary for the assembly of $\alpha$ hemolysin," Biochemical and Biophysical Research Communications, vol. 324, no. 3, pp. 1130-1136, 2004.

[114] C. C. McCormick, A. R. Caballero, C. L. Balzli, A. Tang, and R. J. O'Callaghan, "Chemical inhibition of alpha-toxin, a key corneal virulence factor of Staphylococcus aureus," Investigative Ophthalmology and Visual Science, vol. 50, no. 6, pp. 2848-2854, 2009.

[115] A. C. Weeks, C. L. Balzli, A. R. Caballero, A. Tang, and R. J. O'Callaghan, "Identification and potency of cyclodextrinlipid inhibitors of Staphylococcus aureus $\alpha$-toxin," Current Eye Research, vol. 37, no. 2, pp. 87-93, 2012.

[116] J. H. Freer and J. P. Arbuthnott, "Toxins of Staphylococcus aureus," Pharmacology and Therapeutics, vol. 19, no. 1, pp. 55-106, 1982.

[117] M. Clyne, J. De Azavedo, E. Carlson, and J. Arbuthnott, "Production of gamma-hemolysin and lack of production of alpha-hemolysin by Staphylococcus aureus strains associated with toxic shock syndrome," Journal of Clinical Microbiology, vol. 26, no. 3, pp. 535-539, 1988.

[118] J. J. Dajcs, M. S. Austin, G. D. Sloop et al., "Corneal pathogenesis of Staphylococcus aureus strain Newman," Investigative Ophthalmology and Visual Science, vol. 43, no. 4, pp. 1109-1115, 2002.

[119] G. Supersac, Y. Piémont, M. Kubina, G. Prévost, and T. J. Foster, "Assessment of the role of gamma-toxin in experimental endophthalmitis using a hlg-deficient mutant of Staphylococcus aureus," Microbial Pathogenesis, vol. 24, no. 4, pp. 241-251, 1998.

[120] A. M. Arana, C. L. Balzli, A. C. Weeks, A. Tang, A. R. Caballero, and R. J. O'Callaghan, "Pathogenesis of Staphylococcus aureus endophthalmitis: analysis of alpha-toxin and gamma-toxin in the rabbit anterior chamber," Investigative Ophthalmology \& Visual Science, vol. 53, 2012, E-abstract 2772.

[121] K. Yamashita, Y. Kawai, Y. Tanaka et al., "Crystal structure of the octameric pore of staphylococcal $\gamma$-hemolysin reveals the $\beta$-barrel pore formation mechanism by two component," Proceeding of the National Academy of Sciences of the United States of America, vol. 108, no. 42, pp. 17314-17319, 2011.
[122] A. Gravet, D. A. Colin, D. Keller, R. Girardot, H. Monteil, and G. Prevost, "Characterization of a novel structural member, LukELukD, of the bi-component staphylococcal leucotoxins family," FEBS Letters, vol. 436, no. 2, pp. 202-208, 1998.

[123] S. Szmigieski, G. Prevost, H. Monteil, D. A. Colin, and J. Jelaszewicz, "Leukocidal toxins of staphylococci," Zentralblatt für Bakteriologie, vol. 289, no. 2, pp. 185-201, 1999.

[124] N. Sugawara, T. Tomita, and Y. Kamio, "Assembly of Staphylococcus aureus $\gamma$-hemolysin into a pore-forming ring- shaped complex on the surface of human erythrocytes," FEBS Letters, vol. 410, no. 2-3, pp. 333-337, 1997.

[125] A. R. Caballero, T. J. Foster, I. R. Monk, A. Tang, C. L. Balzli, and R. J. O'Callaghan, "Ocular pathology of a Staphylococcus aureus mutant lacking a recently discovered virulence factor," Investigative Ophthalmology and Visual Science, vol. 51, 2010, E-abstract 3891.

[126] J. D. Fraser and T. Proft, "The bacterial superantigen and superantigen-like proteins," Immunological Reviews, vol. 225, no. 1, pp. 226-243, 2008.

[127] A. R. Caballero, C. C. McCormick, A. Tang, and R. J. O'Callaghan, "Isolation and characterization of a new Staphylococcus aureus protease," Investigative Ophthalmology and Visual Science, vol. 49, 2008, abstract 5514.

[128] N. Balaban and R. P. Novick, "Autocrine regulation of toxin synthesis by Staphylococcus aureus," Proceedings of the National Academy of Sciences of the United States of America, vol. 92, no. 5, pp. 1619-1623, 1995. 


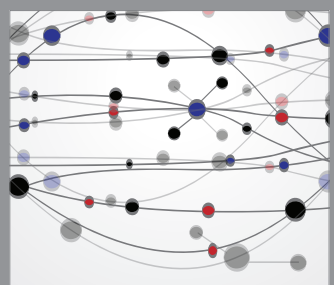

The Scientific World Journal
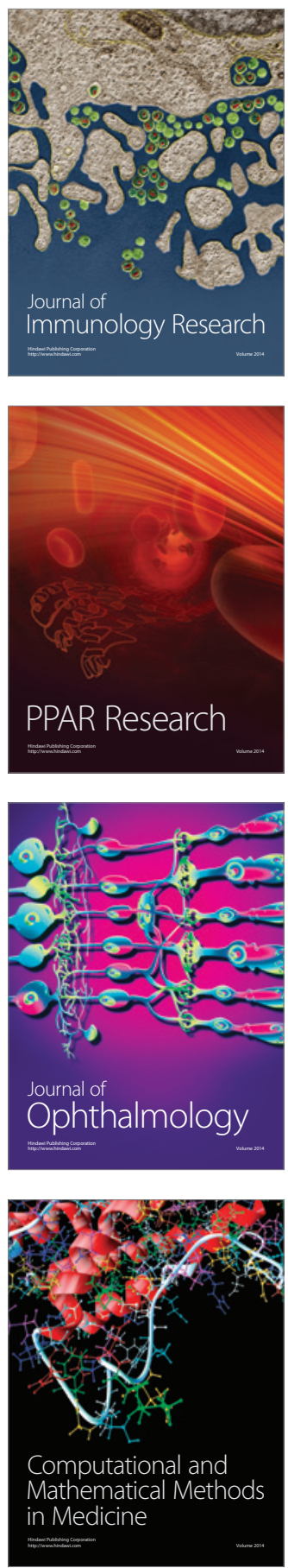

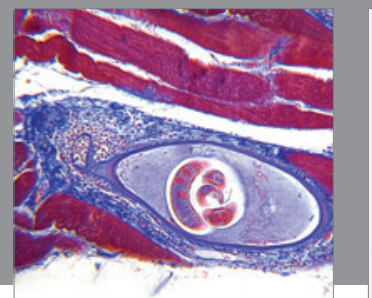

Gastroenterology

Research and Practice
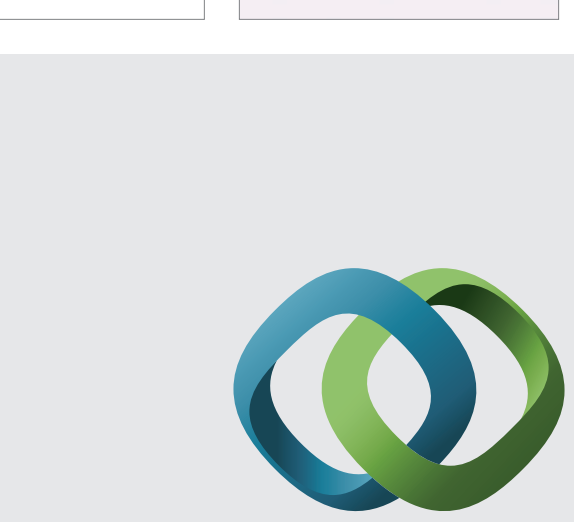

\section{Hindawi}

Submit your manuscripts at

http://www.hindawi.com
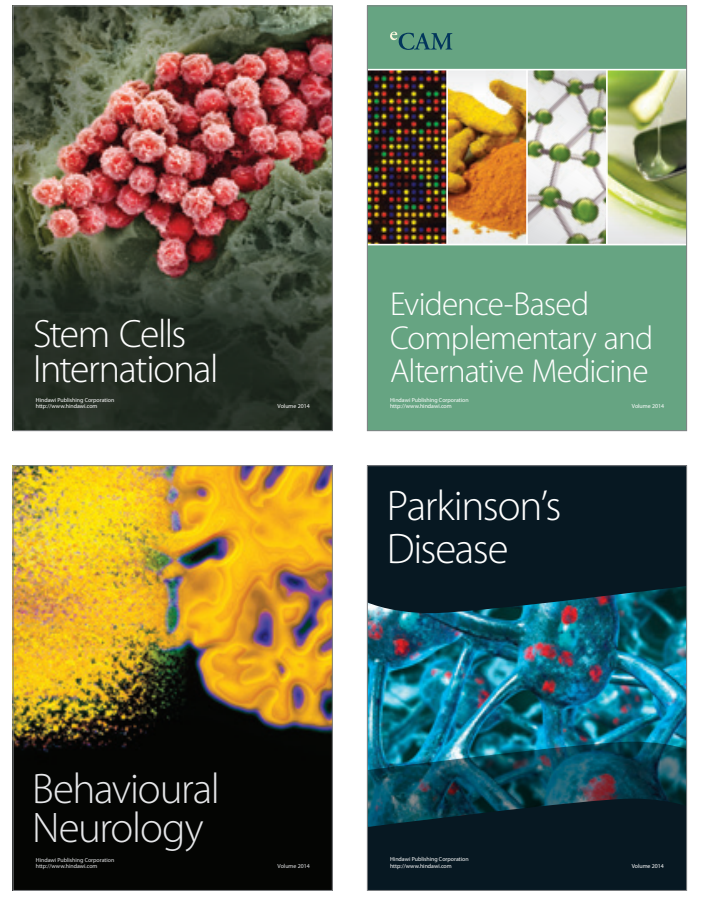
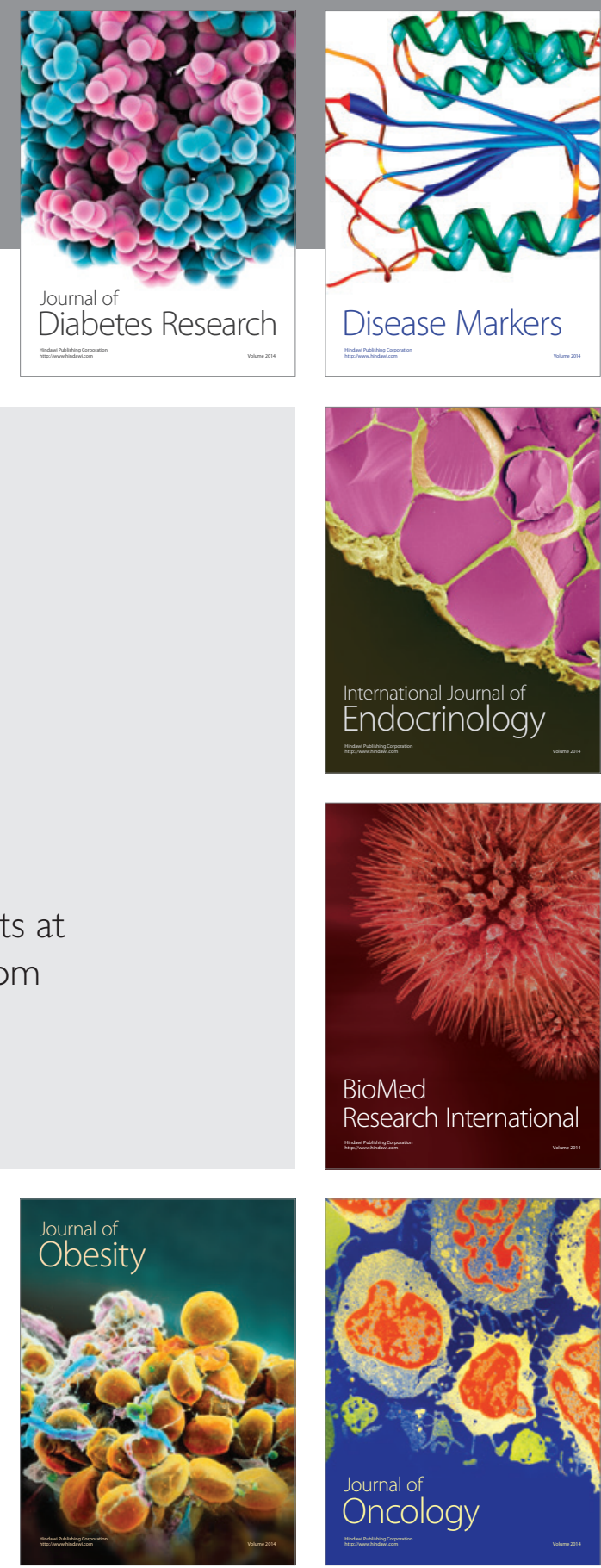

Disease Markers
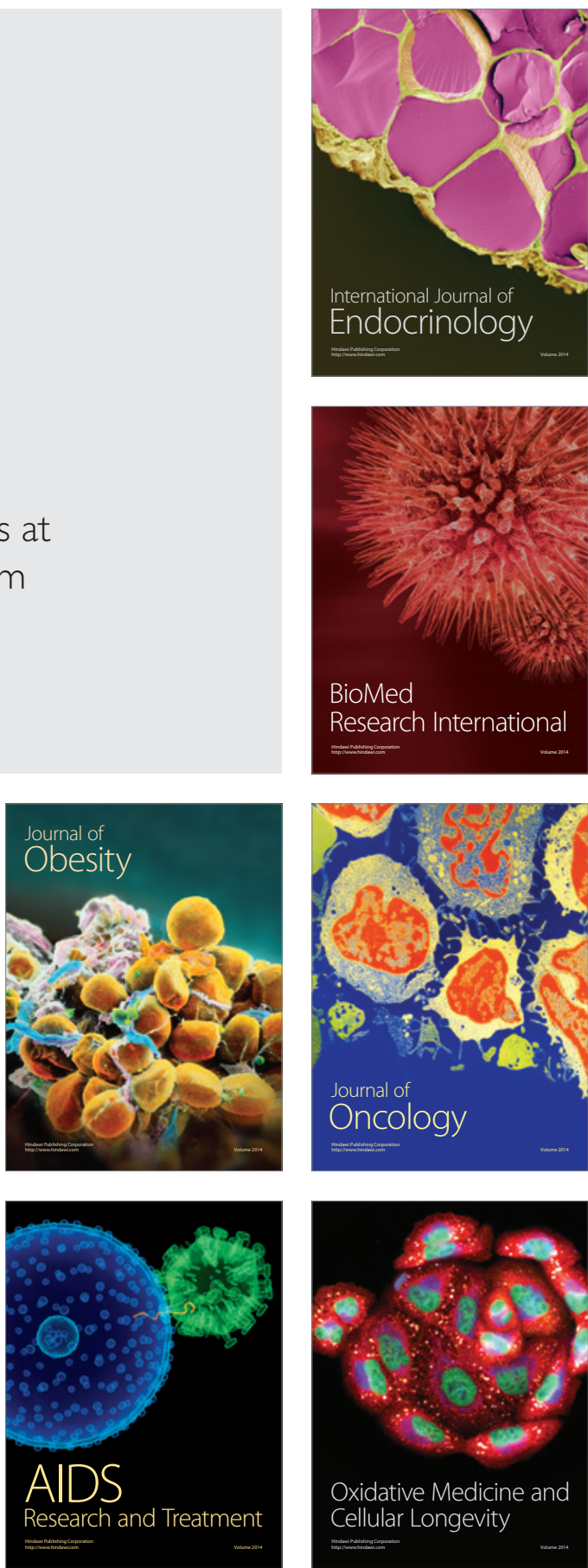